\title{
Demystifying Sensory Processing to Promote Effective Interprofessional and Caregiver Collaboration
}

\author{
Janis Leinfuss \\ Gannon University, janisjsl@yahoo.com \\ Erin O'Hara \\ eringohara@yahoo.com \\ Author(s) ORCID Identifier: \\ (iD) https://orcid.org/0000-0003-3141-7864 \\ (iD) https://orcid.org/0000-0002-4708-8885
}

\section{Recommended Citation}

Leinfuss, J., \& O'Hara, E. (2020). Demystifying Sensory Processing to Promote Effective Interprofessional and Caregiver Collaboration. Student Journal of Occupational Therapy, 1(1), 2-7. https://doi.org/ 10.46409/001.XNEN2575

This OT in Practice is brought to you for free and open access by SOAR @ USA. It has been accepted for inclusion in Student Journal of Occupational Therapy by an authorized editor of SOAR @ USA. For more information, please contactsoar@usa.edu, erobinson@usa.edu. 


\title{
OT in Practice
}

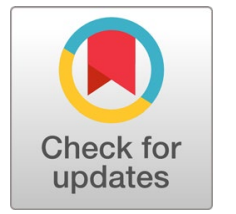

\section{Demystifying Sensory Processing to Promote Effective Interprofessional and Caregiver Collaboration}

\author{
Janis Leinfuss ${ }^{1}$ (D) Erin O’Hara ${ }^{2}$ (D)
}

${ }^{1}$ Gannon University, Post Professional Occupational Therapy Doctoral Program

${ }^{2}$ Allegro School, Cedar Knolls, NJ

\section{DOI: https://doi.org/10.46409/001.XNEN2575}

To cite this article:

Leinfuss, J. \& O' Hara, E. (2020). Demystifying sensory processing to promote effective interprofessional and caregiver collaboration. Student Journal of Occupational Therapy, 1(1), 17-22.

https://doi.org/10.46409/001.XNEN2575

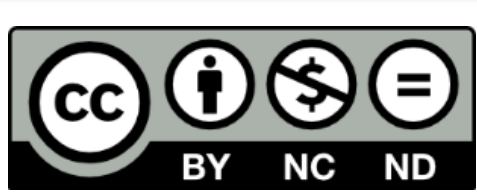

This article is licensed under the Creative Commons Attribution, Non-Commercial, No Derivatives license (CC-BY-NC-ND-4.0). You are free to copy and distribute the work under the following terms: You must give appropriate credit and include a link to the original work. This title page or a standard citation including the DOI link will meet this term. You must also include the link to the CC-BY-NC-ND license. You may not use the material for commercial purposes. If you remix, transform, or build upon the work, you may not distribute that material.

\begin{abstract}
Research shows collaboration and coaching with caregivers and educators positively impacts growth in occupational performance. Better understanding of this additional role that occupational therapy practitioners play; when working with children with sensory processing challenges, is vital to properly advocate for strategies and resources to help them reach their personal trajectory. This article offers insight into the importance of removing professional jargon to facilitate effective interprofessional collaboration. Specific strategies for making coaching and training sessions for sensory processing content relatable and meaningful to educators and caregivers are also provided.
\end{abstract}

Keywords: sensory processing disorder (SPD), interprofessional communication, caregiver collaboration, coaching 


\section{Introduction}

When working with children and adolescents, phrases such as "sensory regulation", "is it sensory?" and "sensory processing disorder" are often heard and sometimes misunderstood by educators and caregivers alike. Therefore, occupational therapists must translate the complex neuroscience language of sensory processing to be meaningful to caregivers and educators. This is necessary to support the generalization of concepts from therapy to application for children with sensory processing challenges. LaFrance et al. (2019) acknowledge that professional language and jargon may be a barrier to interprofessional collaboration. Therefore, it is a responsibility of occupational therapy practitioners to ensure that professional jargon is made understandable with the intention of facilitating sensory processing and maximizing occupational performance. Occupational therapists must build upon the foundational understanding of the five senses for educators and caregivers by providing more information and specific examples to make the information meaningful. The most commonly recognized senses are seeing, hearing, smelling, tasting, and touching. These senses relate to the visual, auditory, olfactory, gustatory, and tactile systems.

In addition to these commonly known senses, there are three lesser known senses that are equally important but can be more difficult to understand. One of these is the vestibular system, which provides a sense of movement and balance. In addition to this, the proprioceptive system provides the sense of position in space and exerted force, while the interoceptive sense offers you information from internal organs (Miller, 2014).

\section{Communicating Sensory Challenges}

Through relatable experiences of how sensory experiences impact the educators and caregivers, occupational therapists can make information about sensory processing and sensory processing challenges meaningful. This can facilitate training and collaboration to support and improve selfperceived efficacy in assisting individuals with sensory processing challenges (Gee \& Peterson, 2016). Further, caregiver education is also a useful method to promote understanding of the root causes of behaviors to build appropriate and valuable intervention strategies (Bulkeley, et al., 2016).

Coaching that utilizes sensory integrative theory shows promise for positively impacting daily occupations for children with autism spectrum disorder (ASD) and their families (Bulkeley, et al., 2016). Occupational therapy practitioners may incorporate coaching and training for caregivers as an evidence-based approach to support their clients with sensory processing challenges.

Providing relatable examples for the lesser recognized senses may limit the need for professional jargon and make the content more meaningful. For example, the vestibular system can be explained by encouraging caregivers and educators to think of their sensory experiences while on a rollercoaster in the dark. As individuals are unable to see their location, they can sense being upside down in the loop. To understand the proprioceptive system, the relatable experience of sitting in a dark theatre may be used. Eyes may be focused on the screen, but individuals can use their proprioceptive system to obtain a water bottle from the cup holder, bring it effortlessly to their mouth, and know how far back to tilt their head to avoid spillage. Further, the proprioceptive system allows the appropriate amount of force to pick up the drink as well as the correct amount of pressure to not crush the bottle. The interoceptive sense allows individuals to know when the restroom is needed and when to stop eating to avoid a stomachache (Miller, 2014).

Following an explanation of the individual sensory systems and their unique role in sensory processing, occupational therapy practitioners may introduce the coordination of sensory systems to help interpret the world around us. Sensory systems are constantly providing information to the brain. The nervous system registers, interprets, and then filters out what information is important to pay attention to versus what is not crucial in that moment. This processing of sensory inputs happens constantly throughout the day even though individuals are not consciously aware as it occurs (Miller, 2014). 
When coaching educators and caregivers about sensory processing, it may be helpful for the occupational therapist to use the analogy of various sized containers. People can be viewed as having different size containers for each of their own individual sensory systems, and there is no right or wrong size for each container. The size of each container varies from person to person, and the amount of input it takes to fill each container is different (Sensational Path, 2017).

Someone who can tolerate a full day of amusement park rides has a very large vestibular container while someone who feels motion sick while riding in a car has a small vestibular container. An individual who likes mild salsa has a smaller gustatory container than an individual who enjoys hot salsa with extra jalapeno peppers. If a person has a large container for auditory input, they will prefer the television on or listen to music whenever possible. The person with a small auditory container likely needs the room quiet when they are trying to work. The people with large sensory containers are the sensory seekers. The individuals with small containers are more likely to be sensorysensitive or avoiders of sensory stimulation (Dunn, 2007).

Most people can easily manage their sensory containers. They avoid certain sounds, smells, or situations because it makes them feel uncomfortable, causes stress, or makes it hard to concentrate. If unavoidable, most people have adequate coping strategies to manage undesirable sensory input. Similarly, each person seeks out certain sensory inputs subconsciously because those sensations make them feel calm or help them function at their best. When someone cannot instinctively manage his or her sensory containers that is called sensory processing disorder (SPD) (Miller, 2014.)

\section{Implications of Sensory Challenges}

The effects of SPD are significant. Research indicates sensory processing challenges can impact learning and participation in daily occupations. Occupational therapy practitioners offer a unique perspective, connecting the neuroscience of sensory processing to the functional implications of occupational performance in children with sensory processing challenges. In an early study, Tomchek et al. (2015) found that sensory processing patterns correlated to receptive and expressive language challenges, and impacted social opportunities. Miller-Kuhaneck and Watling (2018) found that children with difficulties in sensory processing had differences in their ability to participate in daily activities including academics, play, and leisure, when compared to children without sensory processing issues. Additionally, Mills and Chapparo (2018) conducted a study with teachers finding that sensory processing challenges impact student learning in children with ASD.

\section{Coaching for Educators and Caregivers}

Encouraging educators and caregivers to recognize how they regulate sensory information instinctively will provide the opportunity to contemplate the experiences of children and adolescents with sensory processing challenges. Exploration of strategies to instinctively manage sensory containers may provide insight that strengthens the understanding of the experiences of individuals with SPD. When educators and caregivers understand the root causes of the behaviors exhibited, they will be better equipped to support the individuals with SPD and, in turn, facilitate improved occupational participation and learning (Bulkeley, et al., 2016).

Climbing into a car on a summer day with the sun shining directly onto the windshield is an experience that most adults will find relatable. Pose the question: would you start your car and pull out onto the street with the sun blazing into your eyes or would you put on sunglasses or adjust the car's visor? In this scenario, the visual system is being overloaded with stimulation from the sun. It is potentially distracting you from focusing and attending on what your brain knows is the most important, which is driving safely. Most individuals, with the ability to regulate functionally, would use a strategy to manage this sensory overload. In this case, sunglasses or a visor would keep the visual sensory container from overflowing 
and the individual focused on what is critical in that moment.

By urging caregivers and educators to think of the same scenario for individuals with sensory processing challenges, the occupational therapy practitioner is providing the opportunity to contrast the experiences.

The individual with sensory processing challenges cannot accurately manage their sensory containers and therefore, they cannot identify strategies to help them focus on what is important in that moment. This individual may have a tiny visual system container, and it is overflowing from an overload of visual stimulation. This overload of visual stimulation may be demonstrated through behavioral reactions such as refusal to go outside, covering their eyes with their arm, or squinting eyes tightly. These reactions make participation in the occupation of driving challenging or perhaps impossible. The individual with SPD is unable to use a strategy to regulate the amount and type of sensory input and therefore, unable to focus and attend to the task, in this case, driving. However, it is important to recall that sensory processing challenges impact occupational performance and participation for individuals of all ages. Just as a small visual system container may impact the adult's ability to drive a car, a young child's participation in recess or an outdoor physical education class may be similarly impacted.

Additionally, implications are not often limited to one sensory system (as in the example provided for the visual system), but rather individuals are bombarded with sensory information from multiple sensory systems simultaneously with inadequate strategies to effectively regulate their arousal level and manage those sensory containers.

\section{Conclusion}

As described above, sensory processing challenges can impact participation and performance in daily activities (Ismael, et al., 2018; Miller-Kuhaneck \&
Watling, 2018; Pfeiffer, et al., 2011). Our role as occupational therapy practitioners is to recognize these behaviors as clues and support our clients through targeted, evidence-based interventions to appropriately fill or avoid overflowing their specific sensory containers. Case-Smith and Arbesman (2008) assert that sensory-based interventions can positively impact maladaptive behaviors, increase focus and attention, as well as deter self-stimulatory and stereotypic movement patterns. This is further validated by Kim et al. (2012) who reported positive effects on attention, praxis, postural control, and executive functioning skills. Schoen and Miller (2018) confirm that occupational therapy intervention was found to improve adaptive behavior, emotional functioning, and sensory processing as reported by parents.

We have an important responsibility to educate caregivers and educators about the implications of sensory processing challenges so that mutual understanding can be facilitated. Without a solid comprehension of why and how sensory processing challenges affect occupational performance, it may be challenging for educators and caregivers to gain from effective partnerships with occupational therapists. By forging this partnership sensory based activities may then be utilized more effectively to support the individual's regulation, outside of therapy sessions. As occupational therapy practitioners, we know that sensory-based interventions can facilitate occupational performance (Kashefimehr, et al., 2018). Using relatable examples and language free of professional jargon will support the collaborative efforts that are necessary to apply sensory regulation concepts to everyday life.

It is crucial that we translate this information to caregivers and educators in a way that is purposeful and meaningful. Understanding the importance of the role occupational therapy practitioners play when working with children with sensory processing challenges is vital to properly advocate for strategies and resources to help them reach their personal trajectory. 


\section{References}

Bulkeley, K., Bundy, A., Roberts, J., \& Einfeld, S. (2016). Family-centered management of sensory challenges of children with autism: Single-case experimental design. American Journal of Occupational Therapy, 70(5), 1-7. https://doi.org/10.5014/ajot.2016.017822

Case-Smith, J. \& Arbesman, M. (2008). Evidencebased review of interventions for autism used in or of reference to occupational therapy. American Journal of Occupational Therapy, 62(4), 416-429.

https://doi.org/10.5014/ajot.62.4.416

Dunn, W. (2007). Supporting children to participate successfully in everyday life by using sensory processing knowledge. Infants \& Young Children, 20(2), 84-101. https://doi.org/10.1097/01.IYC.0000264477.0 $5076.5 \mathrm{~d}$

Gee, B. M. \& Peterson, T. W. (2016). Changes in caregiver knowledge and perceived competency following group education about sensory processing disturbances: An exploratory study. Occupational Therapy International, 23, 338-345. https://doi.org/10.1002/oti.1435

Ismael, N., Lawson, L. M., \& Hartwell, J. (2018). Relationship between sensory processing and participation in daily occupations for children with autism spectrum disorder: A systematic review of studies that used Dunn's sensory processing framework. American Journal of Occupational Therapy, 72(3), 1-9. https://doi.org/10.5014/ajot.2018.024075

Kashefimehr, B., Kayihan, H., \& Huri, M. (2018). The effect of sensory integration therapy on occupational performance in children with autism. OTJR: Occupation, Participation and Health, 38(2), 75-83. https://doi.org/10.1177/15394492177434 $\underline{56}$
Kim, H. H., Bo, G. H., \& Yoo, B. K. (2012). The effects of a sensory integration programme with applied interactive metronome training for children with developmental disabilities: A pilot study. Hong Kong Journal of Occupational Therapy, 22, 25-30. https://doi.org/10.1016/j.hkjot.2012.05.001

LaFrance, D. L., Weiss, M. J., Kazemi, E., Gerenser, J., \& Dobres, J. (2019). Multidisciplinary teaming: Enhancing collaboration through increased understanding. Behavior Analysis in Practice, 12, 709-726. https://doi.org/10.1007/s40617019-00331-y

Miller, L.J. (2014). Sensational Kids. New York, New York: Penguin Group.

Miller-Kuhaneck, H., \& Watling, R. (2018). Parental or teacher education and coaching to support function and participation of children and youth with sensory processing and sensory integration challenges: A systematic review. American Journal of Occupational Therapy, 72(1). https://doi.org/10.5014/ajot.2016.018481

Mills, C., Chapparo, C., \& Hinitt, J. (2016). The impact of an in-class sensory activity schedule on task performance of children with autism and intellectual disability: A pilot study. British Journal of Occupational Therapy, 79(9), 530-539. https://doi.org/10.1177/0308022616639989

Pfeiffer, B. A., Koenig, K., Kinnealey, M., Sheppard, M., \& Henderson, L. (2011). Effectiveness of sensory integration interventions in children with autism spectrum disorders: A pilot study. American Journal of Occupational Therapy, 65(1), 76-85. https://doi.org/10.5014/ajot.2011.09205

Schoen, S. A. \& Miller, L. J. (2018). A retrospective pre-post treatment study of occupational therapy intervention for children with sensory processing challenges. The Open Journal of Occupational Therapy, 6(1). https://doi.org/10.15453/2168-6408.1367 
Sensational Path. (2017, May 5). What is sensory processing? Do you have a big or a little cup? https://www.sensationalpath.com/sensationalnews/2017/5/4/what-is-sensory-processingdoyou-have-a-big-or-little-cup

Tomchek, S. D., Little, L. M., \& Dunn, W. (2015). Sensory pattern contributions to developmental performance in children with autism spectrum disorder. American Journal of Occupational Therapy, 69(5). https://doi.org/10.5014/ajot.2015.018044 